\begin{tabular}{c} 
journal homepage: http://ijiemjournal. uns.ac.rs/ \\
International Journal of Industrial \\
Engineering and Management \\
Volume $13 /$ No $1 /$ March $2022 / 49-57$ \\
\hline
\end{tabular}

Original research article

\title{
Construction project progress evaluation using a quantitative approach by considering time, cost and quality
}

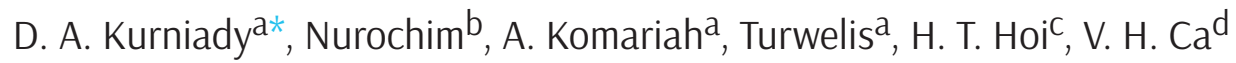 \\ a Universitas Pendidikan Indonesia, Indonesia \\ ${ }^{b}$ Universitas Islam Negeri Syarif Hidayatullah Jakarta, Indonesia \\ ${ }^{c}$ FPT University, Language Department, Vietnam

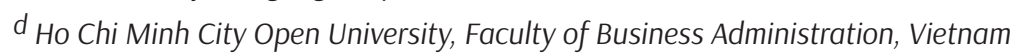

\section{ABSTRACT}

Examining the progress of the project and comparing it with the planned values removes many ambiguities for project management. In this article, a new quantities framework is proposed to evaluate the progress of construction projects with considering different risks. The work progress status (WPS) performance improvement method is based on the performance of input indicators, time, work progress, cost, and two key performance indicators, namely Stakeholder satisfaction performance index and Quality performance index. After the implementation of each step, the actual values of the input factors are identified and compared with the initial program. Results allow project managers to examine the impact of WPS performance on those that have not yet been performed.

\section{Introduction}

Project control has been a popular subject of research for decades [1]. Project management evolved in the second half of the twentieth century, with the use of strategies used by military personnel in World War II to oversee large and complex projects involving thousands of people and extensive military equipment [2]. The basics of project management can also be traced to large government projects in the late nineteenth century, especially those involving the construc-
ARTICLE INFO

Article history:

Received November 23, 2021

Revised January 1, 2022

Accepted January 13, 2022

Published online February 14, 2022

\section{Keywords:}

Construction Projects;

Earned Value Management;

Project Progress Status;

Project Risk Management

* Corresponding author:

Dedy Achmad Kurniady

dedy_achmad@upi.edu 
The main challenge of project management is to meet all project objectives by considering time constraints and budgeting according to customer requirements [8]. The method of work in the project and all the required processes, resources, and budgets are recorded in writing before the start of the project. The main constraints include scope, time, quality, and budget [9]. The second challenge in project management is the allocation and optimal use of primary resources to achieve predefined goals [10]. Aware that most issues in management ultimately focus on efficiency and optimal use of resources. Optimal decision-making is also essential in project selection [2]. A problem that is perhaps one of the most critical issues for organizations and has a special place in academic textbooks is related to economic and technical evaluations and feasibility or issues such as project management and planning [3]. There is management in a broader field in organizations with mature project management and under the influence of project management and portfolio management. Organizational priorities and strategies are linked between portfolios and plans and individual plans and projects. Projects, whether in plans or portfolios, are a means to an end for organizational goals that are often in the context of a strategic plan. If we look at this issue from a systemic point of view, it will be seen that the optimality of a project alone does not mean the best choice for the organization considering all the conditions and other projects of the organization [5], [7], [9]. Instead, each project should be selected in line with other conditions of the organization and according to the overall goals of the organization. Because although individual projects can have different benefits, at a higher level as a project or a portfolio, the benefits of each can affect the benefits of other projects, so organizations need criteria for project prioritization. At their disposal to be able to achieve the most effective way to achieve their strategic goals at the macro-level [6], [10].

Knowing how much a project has deviated from the planned course allows us to estimate project progress in terms of cost and time factors and take remedial or preventive actions if necessary. By determining the risk in each Work Progress Status (WPS), risk management techniques allow us to deterministically estimate and ultimately manage the risks associated with a project [11]. In a study by Moradi et al. [12], they developed an earned value management model for evaluating the progress of a project in terms of time, cost, and scope criteria. This model also considers the project risk under uncertain conditions to improve the accuracy of its predictions.

Khesal et al. [13] proposed an earned value management approach for controlling project time, quality, cost, and risk factors, which uses a new quality control index. In a study by Kamyabniya and Bagherpour [14], they introduced a hybrid approach consisting of earned value management and risk assessment for estimating risk costs and risk performance. Willumsen et al. [15] provided a literature review and an empirical study of project risk management as a tool for value creation. In particular, this study examined the relationship between risk management practices and value creation. Babar et al. [16] presented a risk performance model comprising various performance indicators for better forecasting in earned value management. In a study by Goli et al. [17], a combination of artificial intelligence and meta-heuristic algorithms was used to generate the information needed in project performance predictions. Issa et al. [18] used a fuzzy risk analysis approach to develop a quantitative method for evaluating and selecting construction projects. Khoso et al. [19] designed a robust framework for evaluating contractors in construction projects. For this purpose, they analyzed more than 80 indicators and built the framework with those offering the most reliable assessments. Feng et al. [20] analyzed the process of monitoring construction projects and proposed a method for risk mitigation in these projects. These researchers used the dynamic systems simulation method to analyze their results. In a study by Švajlenka and Kozlovská [21] on timber-based construction projects, they reviewed 160 such projects and assessed their suppliers, project management, and construction quality to analyze their efficiency and sustainability.

The approach presented in this paper allows project managers to consider possible interactions between input factors of a project and infer accordingly how poor performance concerning any of them can affect others and the overall risk of the project. Reviewing the literature, one can see that only some articles have provided quantitative methods capable of supporting project managers in decision-making and enabling them to avoid project risks [22], [23]. Furthermore, while the existing models have only considered the risk associated with the two main performance criteria, namely time and cost, the present study includes five criteria in the evaluations to ensure a more accurate project risk assessment before proceeding to earned value analysis. 


\section{Method}

\subsection{Definition of fundamental concepts}

During the project life cycle, projects begin, and the project manager supervises the project managers and provides them with instructions and guidance. Project managers coordinate efforts between projects but do not manage them. One of the basic responsibilities of project management is identifying, identifying, monitoring, and controlling interdependencies between projects, dealing with aggravating issues among the projects in the project, and following up on the participation of each project and non-project work to integrate project benefits. The integrated nature of project management processes involves coordinating the processes for each project. This applies to all start-up, planning, implementation, monitoring, and control processes and includes process management at a higher level than what is relevant to the project. In addition, these processes can be replicated between the project area and the project. Effective planning for the design requires a top-down approach in the first place and then a bottom-up process. This kind of interrelationship between processes at different levels of design and processes at different levels of the project can be observed at all stages of the design life cycle. An example of this would be scheduling development, where a partial overview of the overall scheduling at the project level is considered to validate the information at the project level. Like the interrelationships between the portfolio area and the project, the relationship between the project and the project is rotational. In the initial phases (initial and planning), the flow of information from the project is towards the projects, and then in the final phases (implementation, control, and closing), this flow is from the project to the project.

In order to demonstrate the progress of a construction project, the Work Progress Status (WPS) should be assessed. Moreover, evaluating how much the project has deviated from the planned course at these control points will allow managers to keep track of the progress and take remedial actions. Such assessments require a series of reliable performance indicators or, in other words, measurable quantitative and qualitative data that offer true insights into the project performance. The relative importance of these indicators and the factors that influence them must be determined by decision-makers. Two very important issues need to be considered in the risk management process. Firstly, since it is time-consum- ing and pointless to analyze all the risks of a project, it is better to identify the underlying risks that have a significant impact on project time and cost. Secondly, once the important risks are identified and analyzed, it is crucial to prepare proper responses to these risks, as risk management is only effective if the emerging risks are promptly eliminated or mitigated through careful advance planning.

\subsection{Algorithm description}

The method of this paper relies on the classic version of the critical path technique to estimate project completion time. In general, the project is divided into a number of WPS control points (i.e. points for controlling progress), which help determine the control time. Upon reaching the designated point, the input factors should be examined and compared with the initial plan/ schedule. Risk monitoring at each WPS enables managers to take remedial and preventive measures for future WPS points. The risk associated with each WPS is determined by performance indicators such as time, work progress, cost, Stakeholder Satisfaction Performance Index (SSPI), and Quality Performance Index (QPI). After deciding which remedial measures to take, the average risk after taking these measures should be compared with the situation resulting from not taking them. If these measures decrease the average risk, the project should continue with new risk values replacing the existing ones. Otherwise, these measures should be ignored, and the previous values should be taken as the final risk. Finally, the project risk is rated, and the obtained risk rating is considered as feedback for preventive measures for the upcoming WPS. The process of earned value analysis is described below.

Sets: The set representing the number of WPSs

$\mathrm{i}=1,2, \ldots, \mathrm{x}$

The set representing the number of activities

$\mathrm{j}=1,2, \ldots, \mathrm{n}$

First, it is necessary to determine the estimates of time $\left(\mathrm{D}_{\mathrm{j}}\right)$ and resources needed $\left(\mathrm{U}_{\mathrm{j}}\right)$ for each activity. The risk associated with each activity $\left(\mathrm{R}_{\mathrm{j}}\right)$ is determined by management. The effort needed in each activity $\left(\mathrm{E}_{\mathrm{p}}\right)$ is determined by Equation (1). The algorithm must be executed sequentially for every WPS.

$E_{i}=D_{j} * U_{j} * R_{j} * W H$

The total effort (TE) needed to complete the project is obtained using Equation (2):

$T E=\sum j=1^{n} \quad E_{j}$ 
Daily working hours $(\mathrm{WH})$, cost of work $(\mathrm{CW})$, activity duration $\left(\mathrm{T}_{\mathrm{j}}\right)$, and the time interval between each two WPS points (TI) are constant throughout the project. Tc is the time required to complete the project. The earliest start time and the earliest end time of each WPS are denoted by $\left(\mathrm{ST}_{\mathrm{i}}\right)$ and $\left(\mathrm{ET}_{\mathrm{i}}\right)$, respectively. The number of WPS points (NWPS) is determined by Equation (3), and their start and end times are given by Equation (4) and (5).

$$
\begin{aligned}
& N W P S=I n t^{+}\left[\frac{T C}{T I}, 0\right] \\
& S T_{i}=\left[E T_{i-1}\right] \\
& E T_{i}=\left[S T_{i}+T_{i}\right]
\end{aligned}
$$

The effort required at each WPS is determined by Equation (6) to (8):

If $\left(S T_{i} \leq S T_{j}\right) \wedge\left(E T_{j} \geq E T_{i}\right)$

Then $E_{i}=\left(T_{j}-\left(E T_{j}-E T_{i}\right) * U_{j} * R_{j} * W H\right.$

If $\left(S T_{j}<S T_{i}\right) \wedge\left(E T_{j}<E T_{i}\right)$

Then $E_{i}=\left(T_{j}-\left(S T_{i}-S T_{j}\right) * U_{j} * R_{j} * W H\right.$

If $\left(S T_{j}<S T_{i}\right) \wedge\left(E T_{j}>E T_{i}\right)$

Then $E_{i}=\left(T_{j}-\left(\left(E T_{j}-E T_{i}\right)+\left(S T_{i}-S T_{j}\right)\right)\right) * U_{j} * R_{j} * W H$

The number of days remaining until the end of the project is (TR), which is calculated using Equation (9) for $\mathrm{WPS}_{1}$ and Equation (10) for other WPSs.

$$
\begin{aligned}
& T R_{1}=\frac{T E-E 1}{W H} \\
& T R_{i}=T R_{i-1}=\frac{E i}{W H} \quad \text { for } i=2, \ldots, x
\end{aligned}
$$

Work progress (WP) is calculated by Equation (11).

$W P_{i}=\frac{E i}{T E}$

The constituent variables of SSPI and QPI are denoted by y and $\mathrm{k}$, respectively. The values of these indicators are obtained by multiplying their constituent variables, i.e., $\mathrm{S}_{\mathrm{Y}}$ for SSPI and $\mathrm{Q}_{\mathrm{K}}$ for QPI by the respective weights as shown in Equations (12) and (13).

$$
\begin{array}{ll}
S S P I_{i}=\Sigma_{y} S_{y} * W_{y} & \mathrm{Y}=1, \ldots, \mathrm{m} \\
Q P I_{i}=\Sigma_{k} Q_{k} * W_{k} & \mathrm{~K}=1, \ldots, \mathrm{Z}
\end{array}
$$

The actual cost of work (ACW) at each stage is calculated by Equation (14).

$$
A C W_{i}=W P_{i} * T E * C W
$$

To determine the risk of each WPS, the standardized factors $\left(\mathrm{F}_{\mathrm{i}, \mathrm{u}}\right)$ must be multiplied by their respective importance weights ( $\mathrm{Wu}$ ) as shown in Equation (15).
$R I_{i}=\Sigma_{a} F_{i, u} * W_{u} \quad$ for $\mathrm{a}=1, \ldots, \mathrm{u}$

Equation (16) and (17) must then be used to calculate the arithmetic mean $\left(\mu_{1} R I_{i, x}\right)$ and the geometric mean of risk $\left(\mu_{2} R I_{i, x}\right)$. Having these means, the total average risk is determined by Equation (18).

$$
\begin{aligned}
& \mu_{1} R I_{i, x}=\frac{\Sigma_{i} R I_{i}}{N W P S} \\
& \mu_{2} R I_{i, x}=\prod i R I_{i}^{1 / n w p s} \\
& \mu R I_{i, x}=\mu_{1} R I_{i, x} * W \mu_{1}+\mu_{2} R I_{i, x} * W \mu_{2}
\end{aligned}
$$

In Equation (19), the earned value $\left(\mathrm{EV}_{\mathrm{i}}\right)$ is obtained by multiplying the budget (BAC) by WP.

$E V_{i}=B A C * W P_{i}$

CPI and SPI are given by Equations (20) and (21).

$C P I_{i}=\frac{E V_{i}}{A C W i}$

$S P I_{i}=\frac{E V_{i}}{P V i}$

The project health $\left(\mathrm{SCI}_{\mathrm{i}}\right)$ is determined by Equation (22).

$S C I_{i}=C P I_{i} * S P I_{i}$

Equation (23) is used to estimate the cost of completing the project (EAC).

$E A C_{i}=\frac{B A C}{C P I_{i}}$

The completion cost required for each WPS separately $\left(\right.$ GIEAC $\left._{\mathrm{i}}\right)$ can be obtained from Equation (24).

$G I E A C_{i}=A C W_{i}+\frac{B A C-E V c}{R M D+W 1+W P * W 2+A C W * W 3+Q P I * W 4+S S P I * W 5}$

To complete the project with the available budget, project performance over of the remaining WPSs should be improved from (CPI) to (TCPI), which is given by Equation (25)

$T C P I=\frac{(B A C-E V i)}{(B A C-A C i)}$

Using Equation (26), project managers can calculate the percentage of completed WPSs (CPMPLETE) as compared with the total number of remaining WPSs.

COMPLETE $=\frac{E V i}{B A C}$ 
Table 1. Relationship between variables

\begin{tabular}{ccccc}
\hline State & Actual resource & Actual time & Actual work & Earliness/tardiness status \\
\hline 1 & Constant & Constant & Constant & on schedule \\
2 & Increase & Decrease & Constant & Ahead of schedule \\
3 & Decrease & Increase & Constant & behind schedule \\
4 & Constant & Increase & Increase & behind schedule \\
5 & Increase & Constant & Increase & on schedule \\
6 & Constant & Decrease & Decrease & Ahead of schedule \\
7 & Decrease & Constant & Decrease & on schedule \\
\hline
\end{tabular}

Also, Equation (27) can be used to compare the actual costs with the initial budget and compute the percentage of financial resources spent on the project

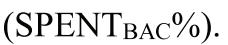

$\% S P E N T_{B A C}=\frac{A C i}{B A C}$

Having the actual values of input indicators, the progress can be controlled.

Step 1: check whether $W P S_{x}=W P S_{n w p s}$. If true, set these values as the final values, otherwise proceed to step 2.

Step 2: record the actual values of each index at the end of $\mathrm{WPS}_{\mathrm{x}}$ and analyze them based on the relationships given in Table 1.

The above table is interpreted using Equation (28):

$E_{j}=D_{j} * U_{j} * R_{j} * W H$

Step 3: define the set $\gamma$ and generate its elements by one of the following equations depending on the situation.

$$
\begin{aligned}
A D_{j, x} & =\frac{A W_{j, x-1}}{A U_{j, x * D W H * R i}} \\
A D_{j, x} & =\frac{A W_{j, x}}{A U_{j, x-1 * D W H * R i}} \\
A D_{j, x} & =\frac{A W_{j, x}}{A U_{j, x * D W H * R i}} \\
A U_{j, x} & =\frac{A W_{j, x-1}}{A D_{j, x * D W H * R i}} \\
A U_{j, x} & =\frac{A W_{j, x}}{A D_{j, x-1 * D W H * R i}} \\
A U_{j, x} & =\frac{A W_{j, x}}{A D_{j, x * D W H * R i}}
\end{aligned}
$$

After determining the new project schedule based on the new values, repeat all calculations in Equation (1) to (15) and temporarily use the results in place of previous values.
Step 4: calculate the new project risk with equation (16) to (18) and compare it with the project risk in the previous state. If $\mu_{R I i, x-1}>\mu_{R I i, x}$, then make all changes permanent, and perform the earned value calculations using Equation (19) to (27), set $\mathrm{X}=\mathrm{X}+1$ and redo the calculations for the new $\mathrm{X}$. Otherwise (i.e. if $\mu_{R I i, x-1}<\mu_{R I i, x}$, meaning that the average risk is higher than before), generate the activities of the set $\gamma$ by Equation (35).

Early/tardy $=\sum j \in \gamma\left|A D_{j . x}-A D_{j . x-1}\right|$

Step 5: define the remedial measures using Equation (36):

$$
\begin{array}{r}
\beta=\left\{W P S_{i,} i=x+1, \ldots, N W P S: S T_{W P S_{i}}>E T_{W P S_{x}} \wedge\right. \\
\left.\exists_{j} \in W P S_{i}: S T_{j} \geq E T_{W P S_{x}}\right\}
\end{array}
$$

After determining the set $\beta$ according to the above conditions, obtain the set ND using Equation (37) if the project is early or Equation (38) if it is tardy.

$$
\begin{aligned}
& N D=\min \{\beta\} \\
& N D=\max \{\beta\}
\end{aligned}
$$

This spreads the existing earliness or tardiness between the remaining WPSs, reducing their risk level.

Step 6: Once ND is obtained, one of the following two states occur:

State 1: If $\mathrm{ND}=\{\varnothing\}$, then the control of this WPS is over; therefore set $\mathrm{X}=\mathrm{X}+1$ and process the next WPS starting over from Equation (1).

State 2: If $\mathrm{ND} \neq\{\varnothing\}$, then add or subtract the time obtained from Equation (35) to the activity in ND based on whether the project is early or tardy. Because of this change, resource calculation must also be done using Equation (39).

$$
U_{j, n e w, x}=\frac{A W j g x}{D j . n e w . x * D W H * R i}
$$




\section{Results and Discussion}

As recommended in [17-21], to give readers a better understanding of the mathematical model, it is applied to an example. In this example, the daily working hours is $8 \mathrm{~h}$, the time interval between WPSs is 4 days, the work cost is 10 dollars per hour, and the resource time and the safety risk of each activity are the values given in Table 1 . The project is scheduled with CPM and the results are reported in Table 1. According to this schedule, the project completion time is 47 days. The average risk of the project at the planning stage is 0.5075 .

In the end, the algorithm reaches $X=10$. In this WPS, in activity $\mathrm{F}$, a constant amount of work is done with more resources, which ultimately brings the total risk of the project to 0.4741 .
Figure 1 shows the effect of activity duration on project completion, which is determined by changing the considered durations and tracking changes in the results.

As shown in Figure 1, increasing the duration of activities greatly prolongs the time it takes to complete the project. This relationship between the duration of activities and the project completion time is completely non-linear. In other words, as activity duration increases, the project completion time increases at an increasing rate. From this, one can conclude that it is critical to analyze activity durations before optimizing the project.

Project management has undoubtedly been one of the most important and widely used branches of management in recent decades. According to the various definitions that have been offered of the project

Table 2. Initial project plan/schedule

\begin{tabular}{ccccccccc}
\hline Activity & Time & Resources & Safety risk & ES & EF & LS & LF & EFFORT \\
\hline A & 11 & 2 & 1.3 & 0 & 11 & 0 & 11 & 228.5 \\
B & 5 & 3 & 1.2 & 0 & 5 & 6 & 11 & 144 \\
C & 15 & 1 & 1.5 & 11 & 26 & 11 & 26 & 180 \\
D & 10 & 2 & 1.1 & 26 & 36 & 37 & 47 & 176 \\
E & 12 & 3 & 1.4 & 26 & 38 & 26 & 38 & 403.2 \\
F & 9 & 1 & 1.3 & 38 & 47 & 38 & 47 & 93.6 \\
\hline
\end{tabular}

Table 3. Earned value analysis of the initial plan/schedule

\begin{tabular}{cccccccccc}
\hline WPS & EV & CPI & SPI & SCI & EAC & GIEAC & TCPI & COMPLITE & SPENTE \\
\hline 1 & 1984 & 1 & 1 & 1 & 12256 & 1984 & 1 & 0.161 & 0.161 \\
2 & 1120 & 1 & 1 & 1 & 12256 & 1120 & 1 & 0.091 & 0.091 \\
3 & 744 & 1 & 1 & 1 & 12256 & 744 & 1 & 0.06 & 0.06 \\
4 & 480 & 1 & 1 & 1 & 12256 & 480 & 1 & 0.039 & 0.039 \\
5 & 480 & 1 & 1 & 1 & 12256 & 480 & 1 & 0.039 & 0.039 \\
6 & 480 & 1 & 1 & 1 & 12256 & 480 & 1 & 0.039 & 0.039 \\
7 & 1264 & 1 & 1 & 1 & 12256 & 1264 & 1 & 0.0103 & 0.103 \\
8 & 2048 & 1 & 1 & 1 & 12256 & 2048 & 1 & 0.167 & 0.167 \\
9 & 2048 & 1 & 1 & 1 & 12256 & 2048 & 1 & 0.167 & 0.167 \\
10 & 880 & 1 & 1 & 1 & 12256 & 880 & 1 & 0.071 & 0.071 \\
11 & 416 & 1 & 1 & 1 & 12256 & 416 & 1 & 0.033 & 0.033 \\
12 & 312 & 1 & 1 & 1 & 12256 & 312 & 1 & 0.025 & 0.025 \\
\hline
\end{tabular}

Table 4. Project plan/schedule at $X=10$

\begin{tabular}{ccccccccc}
\hline Activity & Time & Resources & Safety risk & ES & EF & LS & LF & EFFORT \\
\hline A & 9 & 2 & 1.3 & 0 & 9 & 0 & 9 & 187.2 \\
B & 7 & 2.4 & 1.2 & 0 & 7 & 2 & 9 & 161.28 \\
C & 13 & 1.15 & 1.5 & 9 & 22 & 9 & 22 & 179.4 \\
D & 12 & 1.66 & 1.1 & 22 & 34 & 22 & 34 & 175.3 \\
E & 10 & 2.7 & 1.4 & 22 & 32 & 24 & 34 & 302.4 \\
F & 6 & 1.5 & 1.3 & 34 & 40 & 34 & 40 & 93.6 \\
\hline
\end{tabular}




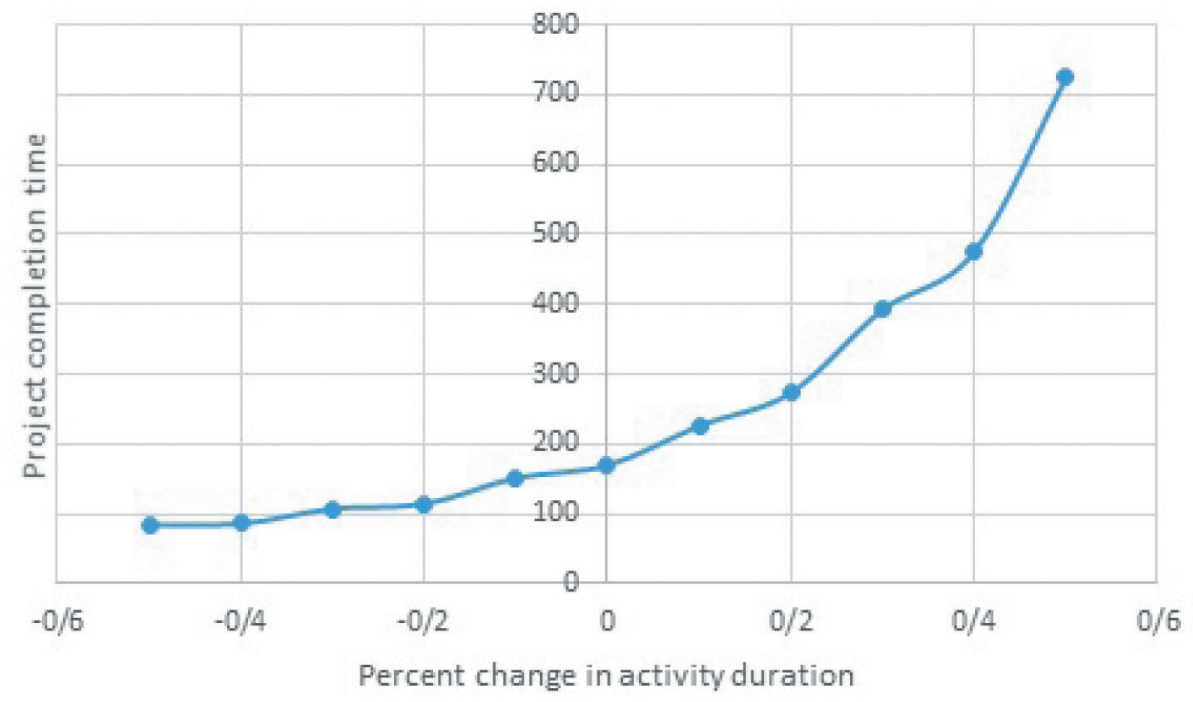

Figure 1. Sensitivity analysis for activity duration

so far, any set of activities that have a beginning and an end and are unique and unique is considered a project. According to this definition, it can be concluded that; many of the events that have taken place in people's lives from the distant past to the present are somehow included in the project definition. With these descriptions, what has caused management and its branches to be considered scientifically, has been the occurrence of the Industrial Revolution and the foundation of a new concept called mass production. With the continuation of such conditions, the advancement of science and technology, and the explosion of information in recent decades, companies and manufacturing and industrial organizations to increase the trade balance and even stay in the competition inevitably change the process. They are the traditional management and the way of their bureaucracy. With such changes, managers of various industries were forced to use new concepts of management science such as change management and project management in different languages and even in different organizations of each country regarding the words of program, plan or project, lexical, semantic and legal differences. There is. Therefore, their framework is not clear and sometimes they are used instead of each other. The goals and objectives set by the government at the level of long-term or strategic planning are called plans, which have qualitative goals, such as the chemical industry development plan the national road network development plan. Achieving these goals and ideals is possible in the long run, usually between ten and twenty-five years. Once the plans have been identified at the long-term planning level, each plan at the mediumterm or tactical planning level is broken down by the top management or the executive system into a set of plans or executive plans that include a set of crosscutting or executive decisions within five to ten Next year; they must implement and achieve the desired results. Each plan is transformed and divided into a set of tasks and operations called a project at the level of short-term or executive planning by headquarters units or middle management levels of the executive system of the country.

\section{Conclusion}

The main challenge of project management is to meet all project objectives by considering time constraints and budgeting according to customer requirements. The method of work in the project and all the required processes, resources, and budget are recorded in writing before the start of the project. The main constraints include scope, time, quality, and budget. The second challenge in project management is the allocation and optimal use of primary resources to achieve predefined goals.

Project management is about knowing exactly what your goals are, how you want to achieve them, what resources you need, and how long it will take you to reach that specific goal. In fact, the goal of project management is to ensure that everyone involved in the project knows all this information and is aware of the purpose of the project. Project management was always done informally, but in the middle of the twentieth century, it emerged as a distinct profession. Project management processes fall into five groups, which include project start, planning, implementation, monitoring and control, and project completion. 
This research was focused on the concept of WPS, and specifically how one can identify the riskiest WPSs and take preventive measures to address their risks. In the numerical example provided in the paper, the average risk of the initial plan/schedule was estimated to be 0.5075 . But after identifying the points where the plan goes off course and taking remedial measures, the average risk dropped to 0.4741 . In other words, the measures taken to address the risk at control points reduced the final risk of the project compared to the original plan. This shows that the measurements and data typically collected by managers for project monitoring purposes can be utilized to balance and mitigate risk throughout the project. It also suggests that slight deviations from the planned course should not be considered inherently intolerable. In some instances, remedial measures provided by this technique can even shorten the span of the project. The method also examines the effect of deviations detected at previous WPS control points on those that are yet to arrive, thus enabling managers to take preventive measures at the right moment.

\section{Funding}

This research did not receive any specific grant from funding agencies in the public, commercial, or not-for-profit sectors.

\section{References}

[1] M. Aldoghan, "To Examine The Mediating Impact Of Work Engagement Among The Relationship Of Human Resource Management Practices And Service Recovery Performance During Pandemic-19," International Journal of eBusiness and eGovernment Studies, vol. 13, no. 1, pp. 23-49, 2021, doi: 10.34109/ijebeg.20211302.

[2] M. N. R. Dias, S. Hassan and A. Shahzad, "The Impact Of Big Data Utilization On Malaysian Government Hospital Healthcare Performance," International Journal of eBusiness and eGovernment Studies, vol. 13, no. 1, pp. 50-77, 2021, doi: 10.34111/ijebeg.202113103.

[3] M. M. Al-Shammari and A.F AlShowaikh, "Investigating User Satisfaction Of Customer Relationship Management In A Telecommunications Company In The Kingdom Of Bahrain," International Journal of eBusiness and eGovernment Studies, vol. 13, no. 1, pp. 97-116, 2021, doi: 10.34111/ijebeg.202113105.

[4] Z. Z. D. Parast, H. Haleh, SA. Darestani, and H. AminTahmasbi, "Green reverse supply chain network design considering ocation-routing-inventory decisions with simultaneous pickup and delivery," Environmental Science and Pollution Research, 2021, doi: 10.1007/s11356-02113770-4. Epub ahead of print. PMID: 34043170.

[5] A. Moshahedi and N. Mehranfar, "A Comprehensive Design for a Manufacturing System using Predictive Fuzzy Models," Journal of Research in Science, Engineering and
Technology, vol. 9, no. 3, pp. 1-23, 2021, doi: https:/doi. org $/ 10.24200 /$ jrset.vol9iss03.

[6] M. Khayatnezhad and F. Nasehi, "Industrial pesticides and a methods assessment for the reduction of associated risks: a Review," Advancements in Life Sciences, vol. 8, no. 2, pp. 202-210, 2021.

[7] P. Kirshkov and A. Nemtsov, "Electrochemical Study of Lanthanum Nickelate Infiltrated into Nanoporous Structure of Strontium Doped Lanthanum Manganite (LSM) for Application as Biological Oxygen Electrode," Progress in Chemical and Biochemical Research, vol. 3, no. 3, pp. 239247, 2020.

[8] R. Rahimian, "Providing Risk Management Strategies in Procurement and Supply Processes," Advanced Journal of Chemistry-Section B, vol. 2, no. 4, pp. 247-253, 2020, doi: 10.22034/AJCB.2020.114274.

[9] A. Samimi, "Risk Management in Information Technology," Progress in Chemical and Biochemical Research, vol. 3, no. 2, pp. 130-134, 2020, doi: 10.33945/SAMI/PCBR.2020.2.6

[10] C. Colicchia, and F. Strozzi, "Supply chain risk management: a new methodology for a systematic literature review," Supply Chain Management: An International Journal, vol. 17, no. 4, pp. 403-418, 2012, doi: 10.1108/13598541211246558

[11] C. Muriana, and G. Vizzini, "A deterministic quantitative technique for assessment and mitigation," International Journal of Project Management, vol. 35, no. 3, pp. 320-340, 2019, doi: 10.1016/j.ijproman.2017.01.010.

[12] N. Moradi, S. M. Mousavi, and B. Vahdani, "An earned value model with risk analysis for project management under uncertain conditions," Journal of Intelligent \& Fuzzy Systems, vol. 32, no. 1, pp. 97-113, 2017, doi: 10.3233/ JIFS-151139.

[13] T. Khesal, A. Saghaei, M. Khalilzadeh, M. Rahiminezhad Galankashi, and R. Soltani, "Integrated cost, quality, risk and schedule control through earned value management (EVM)," Journal of Engineering, Design and Technology, vol. 17, no. 1, pp. 183-203, 2019, doi: 10.1108/JEDT-072018-0119.

[14] A. Kamyabniya, and M. Bagherpour, "Risk-based earned value management: a novel perspective in software engineering," International Journal of Industrial and Systems Engineering, vol. 17, no. 2, pp. 170-185, 2014, doi: 10.1504/IJISE.2014.061992.

[15] P. Willumsen, J. Oehmen, V. Stingl, and J. Geraldi, "Value creation through project risk management," International Journal of Project Management, vol. 37, no. 5, pp. 731-749, 2019, doi: 10.1016/j.ijproman.2019.01.007.

[16] S. Babar, M. J. Thaheem, and B. Ayub, "Estimated cost at completion: Integrating risk into earned value management," Journal of Construction Engineering and Management, vol. 143, no. 3, 04016104, 2017, doi: 10.1061/(ASCE)CO.19437862.0001245 .

[17] A. Goli, H. K. Zareh, R. Tavakkoli-Moghaddam and A. Sadeghieh,"A comprehensive model of demand prediction based on hybrid artificial intelligence and metaheuristic algorithms: A case study in dairy industry," Journal of Industrial and Systems Engineering, vol. 11, no. 4, pp. 190203, 2018.

[18] U. H. Issa, S. A. Mosaad, and M. S. Hassan, "Evaluation and selection of construction projects based on risk analysis," Structures, vol. 27, pp. 361-370, 2020. doi: 10.1016/j.istruc.2020.05.049.

[19] A. R. Khoso, A. M. Yusof, C. Chai, and M. A. Laghari, "Robust contractor evaluation criteria classification for modern technology public construction projects," Journal of Public Procurement, vol. 21, no. 1, pp. 53-74, 2021, doi: 10.1108/JOPP-06-2020-0053.

[20] J. Feng, Y. Wang, and K. Zhang, "Evaluation of the 
quality supervision system for construction projects in China considering the quality behavior risk transmission," Symmetry, vol. 12 , no. 10, 1660, 2020, doi: 10.3390/ sym12101660.

[21] J. Švajlenka, and M. Kozlovská, "Evaluation of the efficiency and sustainability of timber-based construction," Journal of Cleaner Production, vol. 259, 120835, 2020, doi: 10.1016/j. jclepro.2020.120835.

[22] S. A. Zarghami and J. Dumrak, "Application of system dynamics in the assessment of project portfolio performance," International Journal of Industrial Engineering and Management, vol. 11, no. 4, pp. 253-262, 2020, doi: 10.24867/IJIEM-2020-4-269.

[23] L. Hudáková Stašová, "Evaluating the Use of the Activity Based Costing Method in the Construction Industry in the V4 Countries," International Journal of Industrial Engineering and Management, vol. 10, no. 4, pp. 257-268, 2019, doi: 10.24867/IJIEM-2019-4-245. 